\title{
Antioxidants therapy: An alternative for androgen deprivation therapy (ADT) to decrease prostate-specific antigen (PSA) level
}

\author{
Mohammad Reza Naghii ${ }^{*}$, Mehdi Hedayati ${ }^{2}$ and Mahmood Mofid ${ }^{3}$ \\ ${ }^{1}$ Sport Physiology Research Center and Department of Nutrition, Health School, Baqiyatallah (a.s.) University of Medical Sciences, Islamic Republic of Iran \\ ${ }^{2}$ Cellular and Molecular Endocrine Research Center, Research Institute for Endocrine Sciences, Shahid Beheshti University of Medical Sciences, Islamic Republic \\ of Iran \\ ${ }^{3}$ Department of Anatomy, Faculty of Medicine, Baqiyatallah (a.s.) University of Medical Sciences, Islamic Republic of Iran
}

\begin{abstract}
Prostate cancer is a complex, heterogeneous and multifactorial disease. The high prevalence of prostatitis could contribute to prostate carcinogenesis, which is the second most common cause of cancer-related death in males. Unfavorable metabolic profiles such as hormonal imbalances, oxidative stress and inflammation in prostate disorders are associated with several complications. Different strategies of androgen deprivation for advanced prostate cancer are only palliative and rarely cure patients. Following the observed anti-hormonal property, anti-oxidative stress, and anti-inflammatory effects after a combination of dietary antioxidants supplementation in treatment of kidney stone in our original study, we have decided to determine the protective effect of this combination on prostate-specific antigen level. The data obtained from three groups out of eight groups of male Wistar rat (known as: Control, 4 and 8 week antioxidant group) to compare the PSA levels after antioxidants supplementation including, vitamins A, C, E and B6; zinc, selenium and boron. Group 1 (control) was fed a standard commercial diet. Group 2 and 3 received the same diet added with antioxidant nutrients for 4 and 8 week, respectively. Plasma samples collected for analysis. A significant decrease in the plasma concentration of malondialdehyde was noted in the treatment groups (G2 and G3). A marked decrease in the plasma concentration of active androgens (Testosterone, Free Testosterone, and Dihydrotestosterone) was noted in G2 after 4 week treatment. Estradiol concentration significantly increased in G2 and significantly decreased in G3 after 8 week treatment compared with G2. A significant reduction in concentration of CRP in G2 was noted. More specifically, a significant two and four fold lower plasma concentration of PSA was noted in the treatment groups. Data indicated the potential role of the antioxidants combination in decreasing the proposed risk factors of prostate, specifically the PSA level.
\end{abstract}

\section{Introduction}

Unfavorable metabolic profiles such as hormonal imbalances, oxidative stress and inflammation in prostate disorders are associated with several complications. Prostatitis is defined as inflammation of the prostate gland. According to the prostatitis diagnosis guideline, prostatitis could be classified as acute bacterial prostatitis, chronic bacterial prostatitis, inflammatory prostatitis, noninflammatory prostatitis and asymptomatic prostatitis [1], with a prevalence rate of 5 - $9 \%$ and accounts for over 2 million hospital visits annually in the USA [2]. The incidence of asymptomatic prostatitis could be much higher than symptomatic prostatitis and confirmed by notion that both inflammatory cells are found in the prostate biopsy, or leukocytes found in semen analysis from patients without a history of prostatitis [3]. The high prevalence of prostatitis could contribute to prostate carcinogenesis, which is the second most common cause of cancerrelated death in males [4], and is accounted for $28 \%$ of US male cancer cases in 2013 [5]. Prostate cancer (PC) is a complex, heterogeneous and multifactorial disease.

Most prostate tumor growth is initially androgen-dependent or androgen-sensitive [6]. The main circulating androgen, testosterone, is converted to dihydrotestosterone by the isoenzymes $5 a$-reductase 1 and $5 a$-reductase 2 and the latter is the major isoenzyme in the prostate [7]. Although, the association between prostatitis and prostate cancer remains unclear, but a recent study demonstrated that there is a significant positive relationship between prostatitis and prostate cancer, and this conclusion agrees with many previous biological and epidemiological studies which indicate that the inflammatory mediators could promote the prostatic carcinogenesis via multiple signaling pathways [8]. If there is sound evidence relating prostatitis and prostate cancer, it is possible to prevent, or treat prostate cancer by preventing prostatitis. Reducing androgen signaling to the hypogonadal range can reduce prostate cancer growth and patient symptoms and different strategies of androgen deprivation (ADT) for advanced prostate cancer are only palliative and rarely cure patients [9].

Finasteride (5a-reductase 2 inhibitor) and dutasteride (5a-reductase 1 and 2 inhibitor) are commonly used to treat benign prostatic hyperplasia (BPH), a nonmalignant enlargement of the prostate. The potential of these inhibitors through their anti-androgen action has been examined in several clinical trials by decreasing prostate cancer risk by $24.8 \%$ and $23 \%$, respectively, but both inhibitors also

Correspondence to: Mohammad Reza Naghii, Sport Physiology Research Center and Department of Nutrition, Health School, Baqiyatallah (a.s.) University of Medical Sciences, Tehran, Islamic Republic of Iran, E-mail: naghiimr@yahoo.com

Key words: prostate, androgens, oxidative stress, inflammation, prostate-specific antigen

Received: May 11, 2015; Accepted: June 03, 2015; Published: June 06, 2015 
increased the risk of developing high-grade prostate cancer [10,11]. As a result, the Food and Drug Administration (FDA) revised their safety information indicating that they increase high grade prostate cancer in patients [12].

In androgen deprivation therapy (ADT),the potential beneficial role of 5-alpha reductase inhibitors (5-ARI) like finasteride in a primary preventive setting as shown by the prostate cancer prevention trial is partly nullified by the increased incidence of sexual adverse effects compared with placebo $[10,13]$. Treatment of prostate cancer with bilateral orchiectomy, luteinizing hormone-releasing hormone agonist therapy, with and without antiandrogens has been associated with various serious adverse events, including cardiovascular disease, diabetes, and skeletal complications that may also affect mortality [14]. Some studies have reported an association between androgen deprivation therapy (ADT) and increased risk of cardiovascular events [15].

Chronic inflammation as an 'enabling characteristic' is now known to contribute to several forms of human cancer. Inflammation has been implicated as a potential etiological agent in human prostate cancer and risk factors such as prostate inflammation and metabolic disruption have key roles in the development of benign prostatic hyperplasia $(\mathrm{BPH})$ and prostate cancer [16]. Inflammatory cells also secrete cytokines that promote epithelial cell proliferation and stimulate angiogenesis. The role of prostate inflammation as a risk factor for the acute prostatitis in animals was characterized by the leukocyte infiltration, enhanced levels of pro-inflammatory cytokines and chemokines, marked epithelial cell proliferation, activated stromal cells and increase of collagen deposition that was maintained for up to $80 \mathrm{~d}$ after the adoptive transfer of $\mathrm{CD} 8^{+} \mathrm{T}$ cells [17].

It is suggested that the genetic and environmental factors, including the diet and behavior, may influence the PC development [18], and epidemiological data indicates that the consumption of certain types of dietary antioxidants is associated with reduced prostate cancer risk [19]. The results of the studies examining the relationship between prostate cancer and antioxidants remain undefined and inconclusive, with different antioxidants affecting prostate cancer risk differentially. There is no strong evidence for a beneficial effect of selenium, vitamin C, alpha-tocopherol or beta-carotene, whereas lycopene, gammatocopherol appears to be negatively associated with risk of the disease and tea and coffee appear to offer protection against advanced prostate cancer [20]. Among the nutrients, the association of dietary boron and boron compounds with inhibition of activity of prostate-specific antigen and prostate cancer risk has been reported [21-26].

Moreover, several thousand reports have already identified Prostate-specific antigen (PSA) as the most useful biomarker for detecting prostate cancer at an early stage, for evaluating disease progression and for assessing therapeutic response, as well as for identifying tumor recurrence and subsequently emphasized on repeated screening practices for the earliest possible detection of prostate cancer [27]. In fact, this kallikrein-like protease is thought to participate in pathways that are involved in prostate tumor initiation and/or progression, modulated through its hormone dependence. PSA can no longer be regarded as a tissue-specific or tumor-specific marker only for prostatic tissue but as a ubiquitous molecule that can be synthesized and secreted by cells bearing specific steroid hormone receptors under conditions of steroidal modulation or stimulation [28]. Prostatespecific antigen (PSA) and alkaline phosphatase (ALP), and C-reactive protein (CRP) are among analyzed serum markers in chemotherapy in patients with $\mathrm{BPH}$ development and prostate cancer progression [29], and castration-resistant prostate cancer [30]. Although, C-reactive protein (CRP) unlike PSA, is neither organ-specific nor tumor-specific, but its increased values are an independent prognostic marker for tumor-specific survival of patients with prostate cancer [31]. It could, therefore, be an important biomarker for urological cancers.

In an attempt to treat kidney stones, we noticed that elevated concentration of androgens (as promoters of the formation of renal calculi) as a result of EG consumption and their decreasing following antioxidant supplementations along with the marked decrease in malondialdehyde level provides a scientific rational for preventive and treatment roles of antioxidant nutrient complex in kidney stone disease [32], and [submitted manuscript, under consideration]). The underlying mechanism revealed that a combination of dietary antioxidants may have a protective effect against free-radical injury, alterations in steroids (including significant lowering androgen levels), and the reduction of cytokines in stone formation. Following the observed anti-hormonal property, anti-oxidative stress, and antiinflammatory effects after supplementation, since the potential risk factors and the above metabolic profiles and characteristics are common in different prostate disorders, therefore, we have decided to determine the protective effect of this combination of natural antioxidants on PSA level.

\section{Material and methods}

In the original rat kidney stone study, eight groups of rats were divided and analyzed in the study. In the present study we are using the data obtained from three groups out of eight groups (known as: Control, 4 and 8 week antioxidant groups) to compare the PSA levels after antioxidants supplementation. Briefly, male Wistar rats weighing 150-200 g were obtained from the Animal House of Physiology Group- Baqiyattallah University of Medical Sciences. Seven rats in each group (Control vs. 4 and 8 week treatment groups) were weighed and randomly kept in plastic cages in a controlled environment with a 12-hour light/ dark cycle and a constant temperature $\left(22-25^{\circ} \mathrm{C}\right)$ and humidity (55-65\%), with free access to food and water. They had access to normal rat chow diet and water for 7 days before the beginning of experimental protocols. Animals were provided clean cages weekly, for either 4 or 8 weeks. All experiments were performed in accordance to the guidelines of the care of animals and approved by the University's Research and Ethics Committee.

\section{Diets and animal treatments}

Rats in all groups were fed with standard rat chow from Pars Animal Food Co. (Tehran, Iran) and water ad libitum throughout study. According to the manufacturer, it contained 9.0 IU Vit. A, 18.0 ug Vit. E, 3.0 ug Vit. B6, 0.20 ug selenium and 85.0 ug zinc per g of dry food, with no added Vit. $\mathrm{C}$ and boron. The daily supplementation of the nutrients in the diet or the water consumed by the animals was calculated given that a $150-200 \mathrm{~g}$ animal food intake is approximately $20.0 \mathrm{~g} /$ day and drinks water at the rate of $10-12 \mathrm{ml} / 100 \mathrm{~g}$ body weight/ day. Therefore, the supplementation rate was considered to provide the amounts of antioxidant nutrients approximately five to seven times of the natural daily intake. The 4 (G2) and 8 (G3) week treatment groups received the standard diet enriched with $4000.0 \mathrm{ug}$ Vit. E and $1500.0 \mathrm{IU}$ Vit. A for each rat per day added to the diet once a week, and provided daily with $5.0 \mathrm{mg}$ Vit. C, $400.0 \mathrm{ug}$ Vit. B6, $20.0 \mathrm{ug}$ selenium, $12.0 \mathrm{mg}$ zinc, and $2.0 \mathrm{mg}$ boron for each rat per day in their drinking water for the period of 4 and 8 weeks, respectively. Commercial lemon juice as the dietary source of citrate was added to the water at the level of $1 \mathrm{ml} /$ $\mathrm{rat} / \mathrm{d}$ for the groups receiving antioxidant nutrients (G2 and G3). 
To provide the antioxidant nutrients, $300.0 \mathrm{IU}(200.0 \mathrm{mg})$ of a softgel capsule of Vit. E as dl-Alpha Tocopheryl Acetate (Vitane Pharmaceutical Inc., Costa Mesa, California, USA) and 75,000.0 IU of a softgel capsule of Vit. A as Palmitate (Daana Pharma. Co., Tabriz, Iran) was dissolved in $3.0 \mathrm{ml}$ of corn oil and added to $85.0 \mathrm{~g}$ of standard $\operatorname{diet}(\sim 12.0 \mathrm{~g} / \mathrm{rat})$ and given once a week, to provide Vit. E and Vit. A at doses as mentioned above. The control group was given $3.0 \mathrm{ml}$ of corn oil alone added to $85.0 \mathrm{~g}$ of standard diet $(\sim 12.0 \mathrm{~g} / \mathrm{rat})$ once a week.

Pharmaceutical Vit. C [Ascorbic acid] $250.0 \mathrm{mg}$ tablets (Osvah Pharmaceutical Co., Tehran, Iran), Pyridoxine HCL (Vit. B6) $40.0 \mathrm{mg}$ tablets (Ramopharmin Pharmaceutical Lab., Tehran, Iran), Selenium (Selenium Amino Acid Chelate) 200.0 ug dietary supplement capsules (Alfa Vitamins Lab., Inc., Doral, Florida, USA), Zinc (zinc sulfate) $50.0 \mathrm{mg}$ capsules (Alhavi Pharmaceutical Co., Tehran, Iran), and Boric acid (Merck- Germany) as the source of boron was used and added to their drinking water to provide the above mentioned doses / rat/day, respectively. Lime juice (Mahram Co. Group, Shiraz, Iran) was purchased from local market. Fresh Food and water containing the above chemicals was provided three times per week and the consumption was monitored and recorded.

Four and eight weeks after the experimental periods, rats from all groups were anesthetized for the collection of blood by cardiac puncture with a syringe and needle for further biochemical studies. Rats were restrained from food for $12 \mathrm{hrs}$ but had access to drinking water. Since, in rats some parameters such as steroid hormones are subject to circadian rhythm, therefore blood samples were collected at the peak time in the afternoon between 14.0-16.0 P.M. and plasma samples stored frozen until analysis. Commercially available assay kits were used to determine the blood parameter levels. Superoxide Dismutase (SOD) was measured by Photometric method, EPIGENTEK, NY, USA, with the intra-assay coefficients of variation $(\mathrm{CVs}) \%$ of 1.6 .

Glutathione Peroxidase activity (GPx) was measured by Enzymatic Colorimetric method, Enzymatic Colorimetric, Cayman Chemical Company, MI, USA, with the intra-assay coefficients of variation (CVs) \% of 2.1. Malondialdehyde (MDA) content, representing lipid peroxidation, determined by the thiobarbituric acid reactive method was measured by Photometric, Bioassay Systems, CA, USA, with the intra-assay coefficients of variation (CVs) \% and assay sensitivity of 5.5 and $0.1 \mathrm{Mmol} / \mathrm{l}(\mu \mathrm{M})$. Total Testosterone $(\mathrm{T})$, Free Testosterone (FT), Dihydrotestosterone (DHT), and Estradiol (E2) were analyzed by ELISA, Diagnostics Biochem, Canada Inc., Ontario, Canada. The intraassay coefficients of variation (CVs) \% and assay sensitivity were 5.1 and $0.022 \mathrm{ng} / \mathrm{ml}$ for TT; 3.4 and $0.17 \mathrm{pg} / \mathrm{ml}$ for FT; 2.1 and $6.0 \mathrm{pg} / \mathrm{ml}$ for DHT; and 4.4 and $1.0 \mathrm{pg} / \mathrm{ml}$ for E2, respectively. Sex hormone binding globulin (SHBG) was analyzed by ELISA kit, CUSABIO BIOTECH CO., Ltd. Wuhan, Hubei, China, with the intra-assay coefficients of variation (CVs) \% and assay sensitivity of 6.4 and $1.0 \mathrm{ng} / \mathrm{ml}$. High-sensitivity C-reactive protein (hs-CRP) was measured by ELISA method using the kit from CUSABIO BIOTECH, Wuhan, China, with the intra-assay coefficients of variation (CVs) \% and assay sensitivity of 5.5 and $7.8 \mathrm{ng} /$ ml. Interleukin-6 (IL-6) and Interleukin-10 (IL-10) were measured by ELISA method using the kit from KOMABIOTECH Inc., Gangseo-gu Seoul, Korea, with the intra-assay coefficients of variation (CVs) \% and assay sensitivity of 8.7 and $10.0 \mathrm{pg} / \mathrm{ml}$. Alkaline phosphatase (Alk.Ph) activity in rat plasma was measured by kinetic photometric test using a kit from Pars Azmun, Tehran, Iran. Plasma Prostate Specific Antigen (PSA) concentrations were determined by Enzyme Immunoassay method using the kit from CUSABIO BIOTECH, Wuhan, China, with the intra-assay coefficients of variation (CVs) \% and assay sensitivity of 6.9 and $0.195 \mathrm{pg} / \mathrm{ml}$.

\section{Statistical analysis}

Data are expressed as mean \pm SD and a Statistical Package for the Social Sciences [(SPSS 18.0), New York: McGraw-Hill] was used to perform all comparisons. One Way ANOVA (LSD post hoc test) was used for comparison of the mean of the measured plasma parameters. A P-value of $\leq 0.05$ was considered statistically significant for the differences.

\section{Results}

The rats in all groups adjusted to the treatments well, and consumed food and water normally.

The effect of antioxidant treatments on the plasma variables including markers of oxidative stress, hormones and inflammation in different groups obtained from the original study and the newly measured PSA levels is shown in Table 1. A significant decrease in the plasma concentration of MDA was noted in the treatment groups (G2 and G3), followed with a marked increase in the activity of SOD and GPX in G2 after 4 week treatment.

Furthermore, a marked decrease in the plasma concentration of active androgens (T, FT, and DHT) was noted in G2 after 4 week treatment. Estradiol concentration significantly increased in G2 after 4 week treatment and significantly decreased in G4 after 8 week treatment compared with G2. No other major changes noted for SHBG concentrations, and for inflammatory biomarkers; except a significant reduction in concentration of CRP in G2 after 4 week treatment.

Also, a significant lower concentration in alkaline phosphatase level (G2) noted in comparison to the control was altered by a significant increase in G3 after 8 week treatment.

More specifically, a significant lower plasma concentration of PSA was noted between G1 with G2 and G3; and consequently between G3 and G4. The PSA level after 4 and 8 week supplementation was two and four fold lower than the control group, respectively; indicating the

Table 1. Effect of antioxidants supplementation on plasma parameters in the study groups (mean $\pm \mathrm{SD})$.

\begin{tabular}{|l|c|c|c|}
\hline $\begin{array}{l}\text { Group }(\mathrm{n}=7) \\
\text { Variable } \mathbf{\nabla}\end{array}$ & G1 (Control) & G2 (4 wks) & G3 (8 wks) \\
\hline SOD $(\mathrm{U} / \mathrm{ml})$ & $223.0 \pm 45.0$ & $277.0 \pm 67.0$ & $234.0 \pm 64.0$ \\
\hline GPX $(\mathrm{nmol} / \mathrm{min} / \mathrm{ml})$ & $137.0 \pm 31.0$ & $170.0 \pm 50.0$ & $146.0 \pm 55.0$ \\
\hline MDA $(\mu \mathrm{M})$ & $1.18 \pm 0.14^{\mathrm{a}}$ & $0.50 \pm 0.10^{\mathbf{b}}$ & $0.70 \pm 0.20$ \\
\hline $\mathrm{T}(\mathrm{ng} / \mathrm{ml})$ & $2.35 \pm 1.50$ & $1.53 \pm 1.77$ & $1.84 \pm 2.0$ \\
\hline Free. $\mathrm{T}(\mathrm{Pg} / \mathrm{ml})$ & $3.60 \pm 3.00$ & $1.75 \pm 2.46$ & $3.78 \pm 3.41$ \\
\hline DHT $(\mathrm{Pg} / \mathrm{ml})$ & $105.0 \pm 70.0$ & $61.0 \pm 71.0$ & $75.0 \pm 76.0$ \\
\hline E2 $(\mathrm{Pg} / \mathrm{ml})$ & $375.0 \pm 105.0^{\mathbf{b}}$ & $451.0 \pm 91.0$ & $239.0 \pm 66.0^{\mathbf{c}}$ \\
\hline SHBG $(\mathrm{ng} / \mathrm{ml})$ & $73.0 \pm 10.0$ & $78.0 \pm 11.0$ & $77.0 \pm 13.0$ \\
\hline hs-CRP $(\mathrm{ng} / \mathrm{ml})$ & $330.0 \pm 65.0^{\mathbf{c}}$ & $255.0 \pm 88.0$ & $280 \pm 60.0$ \\
\hline IL-6 $(\mathrm{pg} / \mathrm{ml})$ & $213.0 \pm 119.0$ & $215.0 \pm 31.0$ & $181 \pm 26.0$ \\
\hline IL-10 $(\mathrm{pg} / \mathrm{ml})$ & $99.0 \pm 49.0$ & $116.0 \pm 38.0$ & $80.0 \pm 30.0$ \\
\hline Alk $\mathrm{ph}(\mathrm{IU} / \mathrm{L})$ & $129.0 \pm 34.0^{\mathrm{c}}$ & $98.0 \pm 48.0^{\mathbf{b}}$ & $188.0 \pm 54.0$ \\
\hline PSA $(\mathrm{pg} / \mathrm{ml})$ & $2.38 \pm 1.05^{\mathbf{b}}$ & $1.62 \pm 0.94^{\mathbf{b}}$ & $0.65 \pm 0.25$ \\
\hline
\end{tabular}

Data were mean \pm SD

aStatistically significant with G2, and G3

bStatistically significant with G3

'Statistically significant with G2 
potential role of the antioxidants combination in decreasing the PSA level.

\section{Discussion}

The incidence of prostate disorders, especially Prostate cancer is an endocrine-dependent tumor which is associated with total testosterone serum levels [33]. The study was designed to investigate the effect of antioxidants supplementation on prostate-specific antigen (PSA) levels after observing the positive results of the supplementation on hormonal and oxidative stress indices. The data confirmed the repletion of antioxidants resulted in an inverse relationship between antioxidants and PSA values in the supplemented groups. The increased levels of SOD and GPX and significant reduction in androgen concentrations and favorite effects on inflammatory biomarkers were associated with a significant lower PSA levels after 4 and 8 week supplementations, respectively. Moreover, although alkaline phosphatase (Alk.ph) was significantly reduced in 4 week group animals and consequently elevated after 8 weeks, but PSA level continued to decrease throughout the study. Biological studies revealed that active oxygen and nitrogen radicals produced by inflammation tissue increased the risk of cancer by suppressing antitumor activity and stimulating carcinogenesis [34].

The embryonic development, growth and maturation of the prostate relies on androgens, acting through their cognate receptor, the androgen receptor (AR) [35] and most prostate tumor growth is initially androgen-dependent or androgen-sensitive [6]. While androgens are necessary for the development and maintenance of the prostate gland, epidemiologic studies do not consistently find a positive relationship between endogenous serum androgen concentrations and the risk of prostate disease. Long-term intervention studies are needed to truly ascertain the effects of androgen manipulation on prostate tissue and disease risk and available data do not support the notion that restoring serum androgens to normal physiologic ranges drives prostate disease [36].

The association of pretreatment total testosterone (TT) serum levels with prostate cancer is still a controversial topic and baseline TT serum levels might have prognostic potential for assessing treatment response for continuous as well as intermittent androgen deprivation therapy [33]. Dihydrotestosterone has up to a ten-fold higher affinity to the androgen receptor than testosterone, making it a more potent androgen [7]. Results of 2 large randomized trials have demonstrated that $5 \alpha$-reductase inhibitors reduce prostate cancer risk by $20 \%$ to $25 \%$ $[10,11]$ and consequently raised the controversial concerns related to an observed increased risk of high-grade disease [37]. Data demonstrated that androgen-deprivation induced a decrease in the androgen receptor (AR) and prostate-specific membrane antigen (PSMA) levels in androgen-sensitive LNCaP cells, which may be associated with the development of more aggressive disease-state following androgen deprivation therapy [38]. Recently, Opoku-Acheampong et al. demonstrated that $5 a$-reductase inhibitors decrease the risk of lowgrade prostate cancer, suggesting that modifying androgen metabolism may have beneficial effects on prostate health [39]. Altogether, these data suggest that the hormone imbalance, including the decrease of serum testosterone level in men with advancing age, which may promote the development of different prostate disorders, inflammation and pre-neoplastic lesions, could be attenuated by a treatment aiming to increase the androgen-to- $17 \beta$-estradiol ratio in serum. Increased levels of estrogens, whether from environmental or developmental exposures, have long been linked to the development of prostate cancer [40]. A non significant increased estradiol level in week 4 in our data was significantly decreased after 8 week supplementation.
Chronic inflammation is now known to contribute to several forms of human cancer [41]. The role of prostate inflammation as a risk factor is now established that the prostate inflammatory response typically results in major changes in the local microenvironment of epithelial cells of the prostate gland, and the immune cells recruited at prostate inflammatory lesions and myofibroblasts may contribute to the release of numerous pro-inflammatory cytokines and chemokines that in turn can promote the oxidative stress, genomic instability and proliferation of epithelial cells [42]. In another mechanism, the disruption of cytokine production and regulation, including cytokine deficiencies, lead to increased inflammation and cancer, whether in response to infection with a commensal organism or to chemical carcinogens [43].

One of the best surrogates of chronic inflammation in prostate cancer is interleukin-6 (IL-6) which is elevated in patients with untreated metastatic or castration-resistant $\mathrm{PC}$ and correlate negatively with tumor survival and response to chemotherapy [44]. Mixed results reported an association between certain alleles of IL10 and IL8 and prostate cancer [45], and recently reported a lack of association of polymorphisms in the IL1 $\beta$, IL6, IL8 and IL10 and prostate cancer [46]. The serum CRP level of the prostate cancer group was found to be higher than that of the $\mathrm{BPH}$ group [47]. The high dose intravenous ascorbic acid therapy ( $7.5 \mathrm{~g}-50 \mathrm{~g}$ ) affected C-reactive protein levels and pro-inflammation cytokines in cancer patients, including prostate cancer [48]. In general, the administration of antioxidants did not produced any disruption in plasma cytokine levels and in fact resulted in slight reduction of CRP and IL-6.

Although, other randomized studies have shown no benefit to dietary supplementation with selenium, lycopene, or soy in reducing the risk $[49,50]$; in the present study, after supplementation a positive trend was observed between low plasma androgen concentrations with a reduction in MDA and lower levels of PSA, indicating a potential role for lowering the gonadal steroids in higher level of PSA in male rats.

Oxidative stress has been implicated in the etiology of several pathologies including prostate cancer group, and there is an inverse relationship between antioxidants and PSA values in this group. MDA is an end product of lipid peroxidation induced by free radical, and its content could reflect the level of lipid peroxidation in the body. Lower levels of plasma vitamin $\mathrm{C}$ and $\mathrm{E}$ levels and superoxide dismutase and catalase activities with higher levels of alkaline phosphatase (ALP) and lipid peroxidation (LPO) in relation to prostate-specific antigen (PSA) levels in prostate cancer ( $\mathrm{PCa}$ ) patients is reported [51]. Oxidative stress can be suppressed with antioxidants or via a reduction in reactive oxygen species production. Thus, developing new therapeutic agents that reduce oxidative stress might be useful in preventing the tumorigenesis and progression of androgen- dependent prostate cancer [52].

Boron is reported to reduce prostate cancer incidence. In a study by Zhang et al 2001), men who ingested the greatest amount of boron were $64 \%$ less likely to develop prostate cancer (PC) compared to men who consumed the least amount of boron. Boric acid acts to inhibit serine proteases-it decreases PSA by $87 \%$ and reduces tumor size in a prostate cancer mouse model [53]. Results of a study indicated that mice receiving 1.7 or $9.0 \mathrm{mg} / \mathrm{kg} /$ day of boric acid solution orally had decreases in tumor size by $38 \%$ and $25 \%$, respectively. The same groups had drops in PSA (prostate-specific antigen) of $88.6 \%$ and $86.4 \%$, respectively. A decreased amount of mitoses and marked reduction of the histochemical expression of IGF-1 (insulin-like growth factor type 1) was noted as the underlying mechanism [54]. 
The important finding indicated that PSA is not only a biomarker of prostate cancer activity but also a functional enzyme produced by prostate cancer cells that acts to promote its very own tumor growth [55], and the interpretation of the hypothesis given by GallardoWilliams, et al. (2002) [53] indicates that PSA is an enzyme (a serine protease) that frees IGF-1 from insulin-like growth factor binding protein. IGF-1 has been shown to promote the growth of prostate cancer. A reduction in PSA's enzymatic activity should decrease the amount of IGF-1. This in turn should decrease prostate cancer growth. Boric acid is a known inhibitor of several serine proteases. Blood boric acid levels as low as $8 \mathrm{mcg} / \mathrm{ml}$ can inhibit the protolithic activity of PSA. Boric acid administration should therefore reduce PSA. This reduction of PSA should be accompanied by decreased expression of IGF-1 and decreased tumor growth.

Low zinc and low iron prostate tissue levels are associated with biochemical recurrence in prostate cancer [56] and optimal prostate zinc concentration has a protective role against cancer [57]. Zinc ions are effective inhibitors of a number of proteases and In the prostate, zinc ion concentrations are ten times higher than in other bodily fluids and Zinc ions have a strong inhibitory effect on the activity of PSA [58].

Selenium (methylselenocysteine (MSC)) acting as an antiandrogen affected tumor growth of human prostate cancer cells by inhibiting the growth of LNCaP human prostate cancer in vivo accompanied by a decrease in the expression of androgen receptor (AR) and PSA [59]. In healthy volunteers a significant reduction in PSA in the seleniumsilymarin group with no effect on blood testosterone level was reported [60], and Selenium supplementation in patients appeared to have no effect on the incidence of prostate cancer in men at high risk [61].

Initially, The Alpha-Tocopherol, Beta Carotene (ATBC) trial reported a $35 \%$ risk reduction for prostate cancer in male smokers taking $50 \mathrm{mg} / \mathrm{d}$ of vitamin $\mathrm{E}$ for a median of 6.1 years [62]. In a large, long-term trial of male physicians, individual supplements of $400 \mathrm{IU}$ of vitamin $\mathrm{E}$ every other day and $500 \mathrm{mg}$ of vitamin $\mathrm{C}$ daily did not reduced the risk of prostate or total cancer [63]. The long-term effect of vitamin $\mathrm{E}$ and selenium on risk of prostate cancer in relatively healthy men compared with placebo revealed an absolute increase in risk of prostate cancer per 1000 person-years of 1.6 for vitamin E, 0.8 for selenium, and 0.4 for the combination, indicating that vitamin E alone significantly increased the risk of prostate cancer among healthy men [64]. Moreover, it was reported that supplementation of a combination of vitamin $\mathrm{E}$, selenium, vitamin $\mathrm{C}$ and coenzyme-Q10 does not affect serum level of PSA or hormone levels in patients with hormonally untreated carcinoma of the prostate [65]. Recently, Muezzinoglu et al. (2011) suggest that men with high intake of $6 \mathrm{mg}$ boron/d had significantly smaller prostates [66].

\section{Conclusion}

Of therapeutic interest, in our study it has been shown that after a short term supplementation of a combination of natural antioxidants, the experimental groups revealed marked differences in the levels of MDA and the steroid hormones and more specifically a significant reduction in the levels of the prostate specific antigen. Oxidative stress and active involvement of free radical-mediated lipid peroxidationinduced membrane damage associated with antioxidant imbalances are considered as an important mechanism involved in many pathological conditions and have been implicated in the pathogenesis of several systemic diseases such as prostate disorders.

Since prostate cancer is the second most prevalent form of male malignancy, the detection of reduced PSA levels may play an important role in the management of prostate disorders in patients. This illustrates that additional studies are necessary to further establish the support for the potential use of antioxidant therapies in reducing PSA level in the prevention or treatment of prostate events in animals and in men.

\section{References}

1. Ritchie JM, Vial SL, Fuortes LJ, Guo H, Reedy VE, et al. (2003) Organochlorines and risk of prostate cancer. J Occup Environ Med 45: 692-702. [Crossref]

2. Gurunadha Rao Tunuguntla HS, Evans CP (2002) Management of prostatitis. Prostate Cancer Prostatic Dis 5: 172-179. [Crossref]

3. Sharp VJ, Takacs EB, Powell CR (2010) Prostatitis: diagnosis and treatment. Am Fam Physician 82: 397-406. [Crossref]

4. Gregorio DI, Samociuk H, De Chello L, Swede H (2006) Effects of study area size on geographic characterizations of health events: prostate cancer incidence in Southern New England, USA, 1994-1998. Int J Health Geogr 5: 8. [Crossref]

5. American Cancer Society (2013) Cancer Facts Figures: 2013.

6. Wang G, Haile S, Comuzzi B, Tien AH, Wang J, et al. (2009) Osteoblast-derived factors induce an expression signature that identifies prostate cancer metastasis and hormonal progression. Cancer Res 69: 3433-3442. [Crossref]

7. Russell DW, Wilson JD (1994) Steroid 5 alpha-reductase: two genes/two enzymes Annu Rev Biochem 63: 25-61. [Crossref]

8. Jiang J, Li J, Yunxia Z, Zhu H, Liu J, et al. (2013) The role of prostatitis in prostate cancer: meta-analysis. PLoS One 8: e85179. [Crossref]

9. Corona G, Baldi E, Maggi M (2011) Androgen regulation of prostate cancer: where are we now? J Endocrinol Invest 34: 232-243. [Crossref]

10. Thompson IM, Goodman PJ, Tangen CM, Lucia MS, Miller GJ, et al. (2003) The influence of finasteride on the development of prostate cancer. N Engl J Med 349: 215 224. [Crossref]

11. Andriole GL, Bostwick DG, Brawley OW, Gomella LG, Marberger M, et al. (2010) Effect of dutasteride on the risk of prostate cancer. N Engl J Med 362: 1192-1202. [Crossref]

12. (2011) FDA Drug Safety Communication: 5-alpha reductase inhibitors (5-ARIs) may increase the risk of a more serious FDA Drug Safety Communication: 5-alpha reductase inhibitors (5-ARIs) may increase the risk of a more serious form of prostate cancer, U.S. Department of Health \& Human Services. http://www.fda.gov/Drugs/DrugSafety/ ucm 258314.htm

13. Corona G, Gacci M, Baldi E, Mancina R, Forti G, et al. (2012) Androgen deprivation therapy in prostate cancer: focusing on sexual side effects. J Sex Med 9: 887-902. [Crossref]

14. Pagliarulo V, Bracarda S, Eisenberger MA, Mottet N, Schröder FH, et al. (2012) Contemporary role of androgen deprivation therapy for prostate cancer. Eur Urol 61: 11-25. [Crossref]

15. Ziaran S, Goncalves FM, Breza J Sr (2013) Patients with prostate cancer treated by ADT have significantly higher fibrinogenemia than healthy control. World J Urol 31: 289-292. [Crossref]

16. Ørsted DD, Bojesen SE (2013) The link between benign prostatic hyperplasia and prostate cancer. Nat Rev Urol 10: 49-54. [Crossref]

17. Haverkamp JM, Charbonneau B, Crist SA, Meyerholz DK, Cohen MB, et al. (2011) An inducible model of a bacterial prostatitis induces antigen specific inflammatory and proliferative changes in the murine prostate. Prostate 71: 1139-1150. [Crossref]

18. Gerber M (2009) Background review paper on total fat, fatty acid intake and cancers. Ann Nutr Metab 55: 140-161. [Crossref]

19. Neill MG, Fleshner NE (2006) An update on chemoprevention strategies in prostate cancer for 2006. Curr Opin Urol 16: 132-137. [Crossref]

20. Vance TM, Su J, Fontham ET, Koo SI, Chun OK (2013) Dietary antioxidants and prostate cancer: a review. Nutr Cancer 65: 793-801. [Crossref]

21. Gallardo-Williams MT, Chapin RE, King PE, Moser GJ, Goldsworthy TL, et al. (2004) Boron supplementation inhibits the growth and local expression of IGF-1 in human prostate adenocarcinoma (LNCaP) tumors in nude mice. Toxicol Pathol 32:73-8. [Crossref]

22. Gallardo-Williams MT, Maronpot RR, Wine RN, Brunssen SH, Chapin RE (2003) 
Inhibition of the enzymatic activity of prostate-specific antigen by boric acid and 3-nitrophenyl boronic acid. Prostate 54: 44-49. [Crossref]

23. Cui Y, Winton MI, Zhang ZF, Rainey C, Marshall J, et al. (2004) Dietary boron intake and prostate cancer risk. Oncol Rep 11: 887-892. [Crossref]

24. Barranco WT, Kim DH, Stella SL Jr, Eckhert CD (2009) Boric acid inhibits stored $\mathrm{Ca} 2+$ release in DU-145 prostate cancer cells. Cell Biol Toxicol 25: 309-320. [Crossref]

25. Henderson K, Stella SL, Kobylewski S, Eckhert CD (2009) Receptor activated Ca(2+) release is inhibited by boric acid in prostate cancer cells. PLoS One 4: e6009. [Crossref]

26. Muezzinoglu T, Korkmaz M, Nese N, Bakirdere S, Arslan Y, et al. (2011) Prevalence of prostate cancer in high boron-exposed population: a community-based study. Biol Trace Elem Res 144: 49-57. [Crossref]

27. Luthringer TA, Aleksic I, Mouraviev V, Albala DM (2013) PSA Screening for the African American Male: When and Why? J Men's Health 10: 86-90.

28. Mannello F, Gazzanelli G (2001) Prostate-specific antigen (PSA/hK3): a further player in the field of breast cancer diagnostics? Breast Cancer Res 3: 238-243. [Crossref]

29. Menschikowski M, Hagelgans A, Fuessel S, Mareninova OA, Asatryan L, et al. (2013) Serum amyloid A, phospholipase $\mathrm{A}_{2}$-IIA and C-reactive protein as inflammatory biomarkers for prostate diseases. Inflamm Res 62: 1063-1072. [Crossref]

30. Matsuyama H, Shimabukuro T, Hara I, Kohjimoto Y, Suzuki K, et al. (2013) Combination of hemoglobin, alkaline phosphatase, and age predicts optimal docetaxe regimen for patients with castration-resistant prostate cancer. Int J Clin Oncol 19: 946954. [Crossref]

31. Köhler A, Eggers H, Kuczyk MA, Schrader AJ, Steffens S (2013) Utility of the serum CRP value for assessing the prognosis and therapeutic response of urological malignancies. Aktuelle Urol 44: 452-455. [Crossref]

32. Naghii MR, Mofid M, Hedayati M, Khalagi K (2014) Antioxidants inhibition of high plasma androgenic markers in the pathogenesis of ethylene glycol (EG)-induced nephrolithiasis in Wistar rats. Urolithiasis 42: 97-103. [Crossref]

33. Porcaro AB, Petrozziello A, Ghimenton C, Migliorini F, Sava T, et al. (2013) Associations of Pretreatment Serum Total Testosterone Measurements with PathologyDetected Gleason Score Cancer. Urol Int 93: 269-278. [Crossref]

34. Lonkar P, Dedon PC (2011) Reactive species and DNA damage in chronic inflammation: reconciling chemical mechanisms and biological fates. Int J Cancer 128: 1999-2009. [Crossref]

35. Yadav N, Heemers HV (2012) Androgen action in the prostate gland. Minerva Uro Nefrol 64: 35-49. [Crossref]

36. Cooper LA, Page ST (2013) Androgens and prostate disease. Asian J Androl. [doi: 10.4103/1008-682X.122361].

37. Theoret MR, Ning YM, Zhang JJ, Justice R, Keegan P, et al. (2011) The risks and benefits of $5 \alpha$-reductase inhibitors for prostate-cancer prevention. $N$ Engl J Med 365: 97-99. [Crossref]

38. Liu T, Wu LY, Fulton MD, Johnson JM, Berkman CE (2012) Prolonged androgen deprivation leads to downregulation of androgen receptor and prostate-specific membrane antigen in prostate cancer cells. Int J Oncol 41: 2087-2092. [Crossref]

39. Opoku-Acheampong AB, Unis D, Henningson JN, Beck AP, Lindshield BL (2013) Preventive and therapeutic efficacy of finasteride and dutasteride in TRAMP mice. PLoS One 8: e77738. [Crossref]

40. Härkönen PL, Mäkelä SI (2004) Role of estrogens in development of prostate cancer. $J$ Steroid Biochem Mol Biol 92: 297-305. [Crossref]

41. Sfanos KS, De Marzo AM (2012) Prostate cancer and inflammation: the evidence Histopathology 60: 199-215. [Crossref]

42. Mimeault M, Batra SK (2013) Development of animal models underlining mechanistic connections between prostate inflammation and cancer. World J Clin Oncol 4: 4-13. [Crossref]

43. Dranoff G (2004) Cytokines in cancer pathogenesis and cancer therapy. Nat Rev Cancer 4: 11-22. [Crossref]

44. Nguyen DP, Li J, Tewari AK (2014) Inflammation and prostate cancer: the role of interleukin 6 (IL-6). BJU Int 113: 986-992. [Crossref]

45. McCarron SL, Edwards S, Evans PR, Gibbs R, Dearnaley DP, et al. (2002) Influence of cytokine gene polymorphisms on the development of prostate cancer. Cancer Res 62 : 3369-3372. [Crossref]

46. Michaud DS, Daugherty SE, Berndt SI, Platz EA, Yeager M, etal. (2006) Genetic polymorphisms of interleukin-1B (IL-1B), IL-6, IL-8, and IL-10 and risk of prostate cancer. Cancer Res 66: 4525-4530. [Crossref]

47. Kim Y, Jeon Y, Lee H, Lee D, Shim B (2013) The Prostate Cancer Patient Had Higher C-Reactive Protein Than BPH Patient. Korean J Urol 54: 85-88. [Crossref]

48. Mikirova N, Casciari J, Rogers A, Taylor P (2012) Effect of high-dose intravenou vitamin C on inflammation in cancer patients. J Transl Med 10: 189. [Crossref]

49. Fleshner NE, Kapusta L, Donnelly B, Tanguay S, Chin J, et al. (2011) Progression from high-grade prostatic intraepithelial neoplasia to cancer: a randomized trial of combination vitamin-E, soy, and selenium. J Clin Oncol 29: 2386-2390. [Crossref]

50. Marshall JR, Tangen CM, Sakr WA, Wood DP Jr, Berry DL, et al. (2011) Phase III trial of selenium to prevent prostate cancer in men with high-grade prostatic intraepithelia neoplasia: SWOG S9917. Cancer Prev Res (Phila) 4: 1761-1769. [Crossref]

51. Akinloye O, Adaramoye O, Kareem O (2009) Changes in antioxidant status and lipid peroxidation in Nigerian patients with prostate carcinoma. Pol Arch Med Wewn 119: 526-532. [Crossref]

52. Shiota M, Yokomizo A, Naito S (2011) Oxidative stress and androgen receptor signaling in the development and progression of castration-resistant prostate cancer. Free Radic Biol Med 51: 1320-1328. [Crossref]

53. Zhang ZF, Winton MI, Rainey C (2001) Boron is associated with decreased risk of human prostate cancer. FASEB J 15: A1089.

54. Gallardo-Williams MT, Maronpot RR, King PE (2002) Effects of boron supplementation on the morphology, PSA levels, and proliferative activity of LNCaP tumors in nude mice. Proc Am Assoc Cancer Res 43: 77.

55. Webber MM, Waghray A, Bello D (1995) Prostate-specific antigen, a serine protease, facilitates human prostate cancer cell invasion. Clin Cancer Res 1: 1089-1094. [Crossref]

56. Sarafanov AG, Todorov TI, Centeno JA, Macias V, Gao W, et al. (2011) Prostate cancer outcome and tissue levels of metal ions. Prostate 71: 1231-1238. [Crossref]

57. Prasad AS, Mukhtar H, Beck FW, Adhami VM, Siddiqui IA, et al. (2010) Dietary zinc and prostate cancer in the TRAMP mouse model. J Med Food 13: 70-76. [Crossref]

58. Ishii K, Otsuka T, Iguchi K, Usui S, Yamamoto H, et al. (2004) Evidence that the prostate-specific antigen (PSA)/Zn2+ axis may play a role in human prostate cancer cell invasion. Cancer Lett 207: 79-87. [Crossref]

59. Lee SO, Yeon Chun J, Nadiminty N, Trump DL, Ip C, et al. (2006) Monomethylated selenium inhibits growth of LNCaP human prostate cancer xenograft accompanied by a decrease in the expression of androgen receptor and prostate-specific antigen (PSA). Prostate 66: 1070-1075. [Crossref]

60. Vostalova J, Vidlar A, Ulrichova J, Vrbkova J, Simanek V, et al. (2013) Use of seleniumsilymarin mix reduces lower urinary tract symptoms and prostate specific antigen in men. Phytomedicine 21: 75-81. [Crossref]

61. Stratton MS, Algotar AM, Ranger-Moore J, Stratton SP, Slate EH, et al. (2010) Ora selenium supplementation has no effect on prostate-specific antigen velocity in men undergoing active surveillance for localized prostate cancer. Cancer Prev Res (Phila) 3: 1035-1043. [Crossref]

62. (1994) The effect of vitamin $\mathrm{E}$ and beta carotene on the incidence of lung cancer and other cancers in male smokers. The Alpha-Tocopherol, Beta Carotene Cancer Prevention Study Group. N Engl J Med 330: 1029-1035. [Crossref]

63. Gaziano JM, Glynn RJ, Christen WG, Kurth T, Belanger C, et al. (2009) Vitamins E and $\mathrm{C}$ in the prevention of prostate and total cancer in men: the Physicians' Health Study II randomized controlled trial. JAMA 301: 52-62. [Crossref]

64. Klein EA, Thompson IM Jr, Tangen CM, Crowley JJ, Lucia MS, et al. (2011) Vitamin $\mathrm{E}$ and the risk of prostate cancer: the Selenium and Vitamin E Cancer Prevention Trial (SELECT). JAMA 306: 1549-1556. [Crossref]

65. Hoenjet KM, Dagnelie PC, Delaere KP, Wijckmans NE, Zambon JV, et al. (2005) Effect of a nutritional supplement containing vitamin $\mathrm{E}$, selenium, vitamin $\mathrm{c}$ and coenzyme Q10 on serum PSA in patients with hormonally untreated carcinoma of the prostate: a randomised placebo-controlled study. Eur Urol 47: 433-439. [Crossref]

66. Muezzinoglu T, Korkmaz M, Nese N, Bakidere S, Arslan Y, et al. (2011) Prevalence of prostate cancer in high boron-exposed population: a community-based study. Biol Trace Elem Res 144: 49-57. [Crossref]

Copyright: (C) 2015 Naghii MR. This is an open-access article distributed under the terms of the Creative Commons Attribution License, which permits unrestricted use, distribution, and reproduction in any medium, provided the original author and source are credited. 